\title{
Increasing the Productivity of Laser Powder Bed Fusion for Stainless Steel 316L through Increased Layer Thickness
}

\author{
Alexander Leicht (D), Marie Fischer, Uta Klement, Lars Nyborg, and Eduard Hryha
}

Submitted: 4 August 2020 / Revised: 24 October 2020 / Accepted: 7 November 2020 / Published online: 25 November 2020

\begin{abstract}
Additive manufacturing (AM) is able to generate parts of a quality comparable to those produced through conventional manufacturing, but most of the AM processes are associated with low build speeds, which reduce the overall productivity. This paper evaluates how increasing the powder layer thickness from $20 \mu \mathrm{m}$ to $80 \mu \mathrm{m}$ affects the build speed, microstructure and mechanical properties of stainless steel 316L parts that are produced using laser powder bed fusion. A detailed microstructure characterization was performed using scanning electron microscopy, electron backscatter diffraction, and x-ray powder diffraction in conjunction with tensile testing. The results suggest that parts can be fabricated four times faster with tensile strengths comparable to those obtained using standard process parameters. In either case, nominal relative density of $>\mathbf{9 9 . 9 \%}$ is obtained but with the $80 \mu \mathrm{m}$ layer thickness presenting some lack of fusion defects, which resulted in a reduced elongation to fracture. Still, acceptable yield strength and ultimate tensile strength values of $464 \mathrm{MPa}$ and $605 \mathrm{MPa}$ were obtained, and the average elongation to fracture was $44 \%$, indicating that desirable properties can be achieved.
\end{abstract}

Keywords additive manufacturing, EBSD, laser powder bed fusion, productivity, stainless steel, tensile properties

\section{Introduction}

Laser powder bed fusion (L-PBF) is a manufacturing process used for producing metal components by repeatedly applying thin layers of powder and selectively melting them on top of one another using a high-energy laser to create the final geometry (Ref 1). This process allows for the fabrication of complex near-net-shape parts with high accuracy and good quality. With proper handling, it is possible to produce almost fully dense components with properties that are comparable to those from conventional methods or, in some cases, even better (Ref 2). Different sectors, such as aerospace, energy, medical, marine engineering, and automotive, have found L-PBF to be an appealing option given its design freedom and improved mechanical properties. However, one main challenge with LPBF is the relatively low productivity related to a low build speed and consequently a high manufacturing cost. Therefore, L-PBF is used primarily for high-end components, most often within the aerospace or medical industry, in which the production volumes are relatively small, and high costs are acceptable (Ref 3-5).

Most of the research and development on the L-PBF processing of stainless steel $316 \mathrm{~L}$ has so far focused on adjusting the process parameters to increase part quality, which

Alexander Leicht, Marie Fischer, Uta Klement, Lars Nyborg, and Eduard Hryha, Department of Industrial and Material Science, Chalmers University of Technology, Gothenburg, Sweden. Contact e-mail: alexander.leicht@chalmers.se. means optimizing certain areas, such as mechanical properties, relative density, and surface roughness. For example, Greco et al. (Ref 6) revealed that similar densities can be achieved with different volumetric energy densities as long as the laser penetration depth is sufficiently high. Liu et al. (Ref 7) revealed that using an increased scan speed changed the microstructure, namely the size of the cells inside the larger elongated grains. Sun et al. (Ref 8), on the other hand, maintained the volumetric energy density at a constant $104 \mathrm{~J} / \mathrm{mm}^{3}$ but alternated the scan speed, hatch distance, and power and showed differences in microstructure and tensile properties. Furthermore, Leicht et al. (Ref 9) showed that increasing the hatch distance and scan speed can excessively increase the number of defects. In a study by Liverani et al. (Ref 10), it was demonstrated that the density decreases when the laser power is too low. However, Leicht et al. and Liverani et al. did not observe large variations in tensile strength. Meanwhile, the work by Tsopanos et al. (Ref 11) demonstrated the effect of laser power and laser exposure time on the porosity of lattice structures. Based on the previous research, it is clear that the process parameters strongly affect the microstructure, defect formation, and tensile properties.

However, little attention has been given to increasing the build speed by alternating the process parameters. As emphasized by Babu et al. (Ref 12), the process must be further developed for high productivity, especially for low-cost materials. Leicht et al. (Ref 9) and Sun et al. (Ref 13) both noted that the build speed can easily be improved by increasing the scan speed and hatch distance, while good mechanical properties can still be maintained. Several other studies have emphasized that increasing the layer thickness can be suitable for increasing the productivity. Wang et al. (Ref 14) revealed that fully dense $316 \mathrm{~L}$ components with good tensile properties can be made with layer thicknesses of $150 \mu \mathrm{m}$; however, no information on the microstructure was provided in their study. Shi et al. (Ref 15) fabricated fully dense Ti-6Al-4V parts with $200 \mu \mathrm{m}$ layer thicknesses. Along similar lines, Ma et al. (Ref 16) fabricated 
fully dense $1 \mathrm{Cr} 18 \mathrm{Ni}$ Ti stainless steel samples and found that by varying the layer thickness between 60 and $150 \mu \mathrm{m}$, they can establish a threshold value of approximately $80 \mu \mathrm{m}$ layer thickness, above which decreased tensile strength was observed. Increasing the layer thickness could easily reduce the production time, which in turn considerably reduces the cost of production. The downside is that increasing the layer thickness might reduce the part quality, which could result in undesirable traits, such as reduced accuracy, increased surface roughness, or lower relative density (Ref 17-20). Nevertheless, certain components are not limited by having somewhat lower performance in these aspects; in fact, each application has its own requirements, and for certain applications, it is not necessary to have full density or very good surfaces. For example, components that require post-treatments such as machining will have limited surface requirements. Parts that are exposed to low and especially static loads (e.g., components for the consumer market and chemical industry) are not significantly affected by reduced density. In fact, the automotive industry utilizes a large volume of powder metallurgy parts, characterized by the density level between 90 and 95\% (Ref 21 ), indicating that AM processing with a high build speed and hence lower costs can be attractive for low-scale manufacturing and spare parts for automotive industry.

To use a higher layer thickness in an optimum way, acceptable levels of controllable defects must be guaranteed to ensure the integrity of the end product and its required properties. The aim of this study is to provide a detailed microstructure characterization and a mechanical properties analysis for samples produced with $20 \mu \mathrm{m}$ and $80 \mu \mathrm{m}$ layer thicknesses, respectively. In particular, this study demonstrates how the build rate can be increased by a factor of four. To date, no pre-developed process parameters exist for the $80 \mu \mathrm{m}$ layer thickness, and thus an optimization of process parameters was conducted prior to the final evaluation of the material-processproperties relationship.

\section{Method}

Gas-atomized stainless steel $316 \mathrm{~L}$ powder with a size distribution of $20-53 \mu \mathrm{m}$ was used as a feedstock material; the chemical composition of the powder is provided in Table 1 and is within the required specification from the machine provider. Samples used in this study were produced using an EOS M290 system flushed with high-purity argon gas to retain the oxygen content in the build chamber at below $0.1 \%$. The machine is equipped with a $\mathrm{Yb}$-fiber laser with a maximum nominal power of $400 \mathrm{~W}$ and laser spot diameter of approximately $100 \mu \mathrm{m}$. The samples were produced using a stripe-scanning strategy, in which a $67^{\circ}$ scan rotation was performed after each layer.

The system was equipped with powder bed and optical tomography monitoring systems, provided by EOS GmbH. The optical tomography (OT) system is based on an sCMOS (scientific complementary metal-oxide semiconductor) highspeed camera that observes the entire building platform at all times. The acquired data from the OT system represents the integral of process radiation from the building platform over a certain time. This system allows for analyzing the homogeneity and stability of the building process.

To determine the process window for manufacturing stainless steel $316 \mathrm{~L}$ with an $80 \mu \mathrm{m}$ layer thickness, 41 cubes were manufactured using the process parameters provided in Table 2. The samples were sorted based on the volumetric energy density (VED), defined by $V E D=\frac{P}{v * h * t}\left(\right.$ in $\left.\mathrm{J} / \mathrm{mm}^{3}\right)$ with power P (W), scan speed $\mathrm{v}(\mathrm{mm} / \mathrm{s})$, hatch distance $\mathrm{h}(\mathrm{mm})$, and layer thickness $\mathrm{t}(\mathrm{mm})$. The VED ranged from $19 \mathrm{~J} / \mathrm{mm}^{3}$ to $77 \mathrm{~J} / \mathrm{mm}^{3}$. Five different process parameter sets were selected (see "Productivity and Sample Selection" section) based on the porosity, productivity, and stability of the process. These process parameters were used to fabricate 10 tensile bars for each set. The set of process parameters that lead to the best tensile properties and productivity was selected for a more extensive characterization; these parameters are presented in Table 3. Figure 1 presents the drawing of the samples that were fabricated to their near-net-shape according to the ASTM E8/ E8M - 16a standard. Additional samples were fabricated using standard process parameters for a $20 \mu \mathrm{m}$ layer thickness developed by EOS GmbH for stainless steel 316L (version 1.10). All the tensile test bars were built vertically along the building orientation, as presented in Fig. 1. The samples were removed from the build plate using a band saw and were characterized in an as-built condition.

The microstructure was examined from a vertical section at the center of the tensile test bars. Samples for metallography were prepared through grinding using $\mathrm{SiC}$ paper and following the recommendation for stainless steel as provided by Struers. The cross section was polished using an MD-Mol polishing disk with a $3-\mu \mathrm{m}$ suspension and an MD-Chem with OP-S as the final step. The porosity was measured on the as-polished samples and then analyzed by a thresholding procedure using ImageJ. Images were taken from the entire surface of several different cross sections - both parallel and perpendicular to the building direction. In total, 10 images at a magnification of $200 \times$ were obtained from each cross-section and then analyzed by a thresholding procedure using ImageJ. A light optical microscope (ZEISS Axioscope 7) was used in combination with a FEG-SEM (Leo Gemini 1550) to evaluate the porosity and microstructure at various magnifications. The average cell

Table 2 Process parameter variations used for determining the process window

\begin{tabular}{ll}
\hline Laser power & $220-370 \mathrm{~W}$ \\
Scan speed & $800-2100 \mathrm{~mm} / \mathrm{s}$ \\
Hatch distance & $0.09-0.12 \mathrm{~mm}$ \\
Stripe width & 5 and $10 \mathrm{~mm}$
\end{tabular}

Table 1 Chemical composition of the powder

\begin{tabular}{lccccccccrrrrr}
\hline Element & Fe & C & Cr & Mn & Mo & N & Ni & O & P & S & Si \\
\hline wt.\% & Bal. & 0.009 & 17.4 & 1.6 & 2.7 & 0.06 & 13.4 & 0.04 & 0.006 & 0.005 & 0.3 \\
\hline
\end{tabular}


Table 3 Selected process parameters for further characterization

\begin{tabular}{lcccc}
\hline Power & Layer thickness & Scan speed & Hatch distance & Stripe width \\
\hline $295 \mathrm{~W}$ & $0.08 \mathrm{~mm}$ & $800 \mathrm{~mm} / \mathrm{s}$ & $0.12 \mathrm{~mm}$ & $10 \mathrm{~mm}$ \\
\hline
\end{tabular}

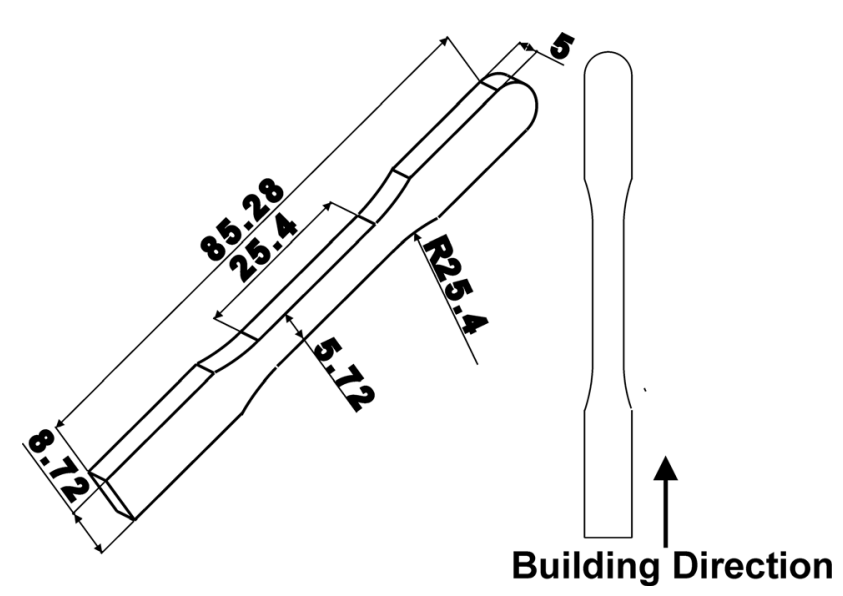

Fig. 1 Schematic overview of sample dimensions and built orientations

Table 4 Predicted build speed for the different layer thicknesses

\begin{tabular}{lcc}
\hline No. of part & Layer thickness, $\boldsymbol{\mu m}$ & Build speed, $\mathbf{~ c m}^{\mathbf{3}} \mathbf{h}$ \\
\hline \multirow{2}{*}{250} & 20 & 5.4 \\
& 80 & 23.2 \\
16 & 20 & 3.6 \\
& 80 & 14.4 \\
\hline
\end{tabular}

size was determined by following the line intercept procedure provided in ASTM E112-13. The sizes were measured by counting more than 1000 intercepts from 10 random SEM micrographs from each condition. An electron backscattered diffraction analysis (Nordlys II detector) was conducted using a $20-\mathrm{kV}$ acceleration voltage and a step size of $1.5 \mu \mathrm{m}$ to evaluate the grain morphology and crystallographic orientation. High angle grain boundaries were defined by having a minimum of $10^{\circ}$ misorientation. The orientation maps were acquired and processed using the Channel 5 software. The x-ray diffraction (XRD) patterns were obtained using $\mathrm{CrK} \alpha$ radiation in a Bruker AXS D8 Advance over a $2 \theta$ range between $30^{\circ}$ and $140^{\circ}$. The ICDD-card 00-033-0397 was used to identify the peaks.

Tensile tests were conducted using an Instron 5500R tensile testing machine, the test was performed using strain control with a crosshead velocity of $0.025 \% / \mathrm{s}$. The strain was measured using a clip-on extensometer with a span of $10 \mathrm{~mm}$; the limited span corresponds to approximately $30 \%$ elongation. When the full distance of the extensometer was reached, the tensile test was paused, and the test was continued until fracture with load control. For this reason, stress-strain curves can only be shown at a point up to $30 \%$ elongation. It should be noted that the ultimate tensile strength can still be acquired.

\section{Results and Discussion}

\subsection{Productivity and Sample Selection}

The productivity of L-PBF is often limited by the time needed to melt and solidify the material. Therefore, the productivity - in other words, the building speed - was evaluated as the volume of material that the process can melt per time unit, which in this case is $\mathrm{cm}^{3} / \mathrm{h}$. The building speed was estimated by preparing two different build jobs with 10x10x10 $\mathrm{mm}$ cubes using EOS print 2.5. EOS print is a commercial software used to prepare the build jobs files and allows for the build time of a job to be simulated from the point when the operator starts the machine. By comparing the software's estimation to the actual build time for more than 10 different builds, only a minor difference (i.e., 2-3\%) between the simulated and actual times can be noted. The difference could originate in various factors, such as uncertainties in the software, estimations of recoating time, or the switch speed between scanned areas. The first build job was simulated with 250 cubes and the second with 16 cubes; both jobs were simulated using the process parameters provided in Table 3, and the results from the simulations are summarized in Table 4. The simulation results indicate that increasing the layer thickness from $20 \mu \mathrm{m}$ to $80 \mu \mathrm{m}$ could reduce the building time to one-fourth of the original duration. It is worth noting that standard EOS process parameters use a layer thickness of $20 \mu \mathrm{m}$, whereas there are available process parameters by other suppliers and published in the literature that have a larger layer thickness (e.g., 30 or $40 \mu \mathrm{m}$ ), indicating a lower build time reduction. In addition, the results reveal that increasing the build plate utilization (i.e., the number of parts on the build plate) increases the building speed. The reason the building speed is different depending on plate utilization is that the time for recoating a powder layer and lowering the build plate is constant regardless of the number of parts used for the setup. It should be noted that the build speed per layer is not influenced by the build height so long as the melting area is the same. Furthermore, each process parameter set used for finding the process window was simulated. The simulation reveals that there should be no specific trend between the VED and the build speed, as indicated by the red line in Fig. 2 .

To determine the process window, 41 cubes were manufactured using the approach outlined in the method section; the porosity of each sample was evaluated, and the results are presented in Fig. 3. The graph shows that VEDs greater than $30 \mathrm{~J} / \mathrm{mm}^{3}$ generated a porosity content below $0.5 \%$, and using the minimum porosity as a criterion, the optimum process window appears to be between $37 \mathrm{~J} / \mathrm{mm}^{3}$ and $65 \mathrm{~J} / \mathrm{mm}^{3}$. More than 15 of the process parameter sets generated a porosity level below $0.1 \%$. Two factors were used to decide between these samples, namely the build speed and the process stability. The process stability was evaluated using the monitoring systems available on the machine. From the OT analysis, the standard deviation of the grey values (i.e., melt pool intensities) was 


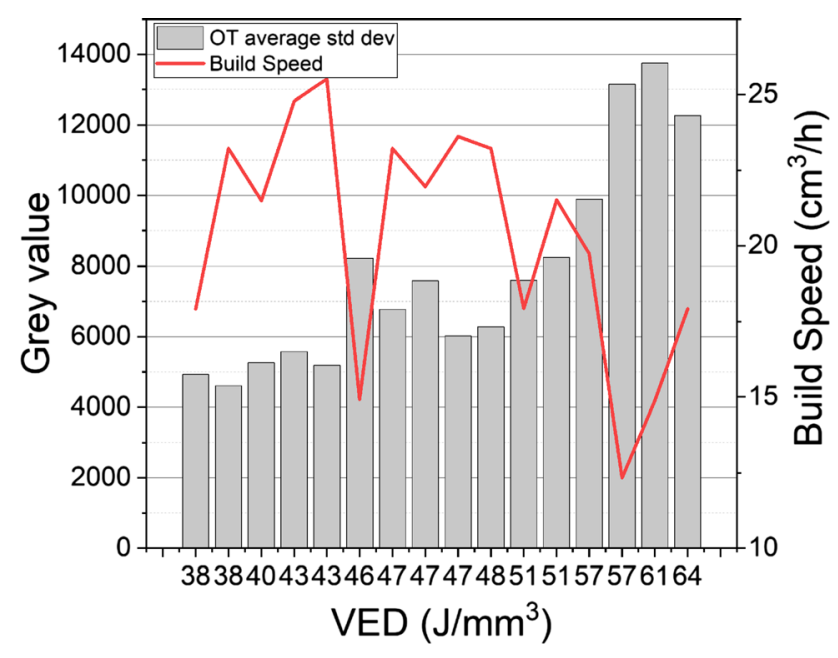

Fig. 2 Gray value standard deviation and build speed versus volumetric energy density

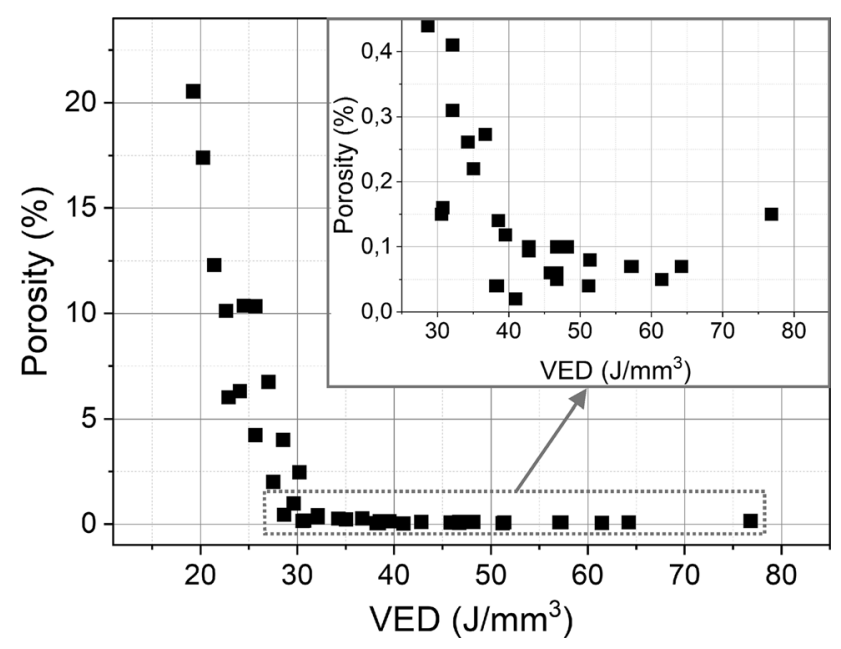

Fig. 3 Porosity versus volumetric energy density

extracted for each cube and layer. A low standard deviation indicates that the intensities throughout the sample tend to be close to the mean, while a high standard deviation indicates a wider spread of intensities within the specimen and hence a less stable process. The average standard deviation for all layers was calculated for each sample and is represented in Fig. 2 along with a simulated build speed (simulated with 250 cubes of size $10 \times 10 \times 10 \mathrm{~mm}$ ) for the 15 samples that reveal a porosity level below $0.1 \%$.

It appears that the standard deviation of the grey values increases globally with an increasing VED. This observation along with the process monitoring data indicates that the process becomes unstable for a VED greater than $50 \mathrm{~J} / \mathrm{mm}^{3}$. A high VED may result in keyhole mode melting which leads to the formation of defects and a less robust process (Ref 22). Five parameter sets were selected with a low grey value standard deviation and a high build speed; the results below are presented only for the parameter set that exhibited the best tensile properties. The selected parameters resulted in an energy density of $38 \mathrm{~J} / \mathrm{mm}^{3}$ and the highest build rate among the 15 samples. Each further characterization was conducted on the
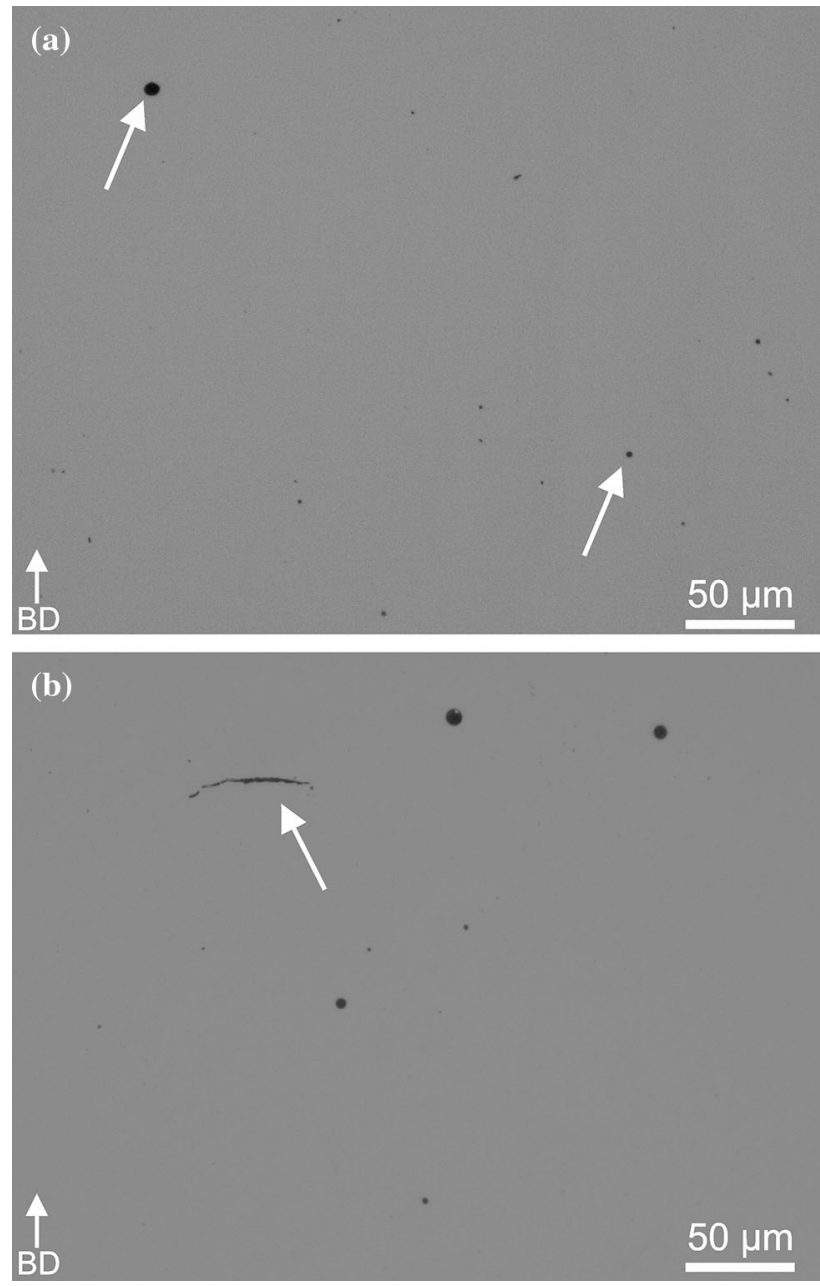

Fig. 4 Light optical images showing the morphology of the observed defects on (a) samples produced with a $20 \mu \mathrm{m}$ layer thickness and (b) samples produced with an $80 \mu \mathrm{m}$ layer thickness

samples that were manufactured with this parameter set (see Table 3).

\subsection{Defects}

Figure 4 provides two representative low-magnification light optical images of the two layer thicknesses. The samples produced with a $20 \mu \mathrm{m}$ layer thickness possess few defects. The observed defects were gas porosities less than $5 \mu \mathrm{m}$ in diameter, indicated by the arrows in Fig. 4a; no cracks or lack of fusion was observed in the samples produced with a layer thickness of $20 \mu \mathrm{m}$. For the samples produced with an $80 \mu \mathrm{m}$ layer thickness, more frequent and larger defects were observed, as presented in Fig. 4b. At a higher magnification, large defects and unmelted metal particles were observed in conjunction with gas-induced porosity. Gas porosity is commonly created by entrapped gas from the feedstock powder or from the entrapped gas in the bottom of the melt pools during the melting and solidification (Ref 16). Furthermore, several line-type defects with lengths from around 25 to $50 \mu \mathrm{m}$ were observed, as indicated by an arrow in Fig. 4b. These defects were randomly distributed throughout the sample. Inside such a defect, traces of metal powder particles could be observed, and the defect seemed to orient along the melt pool boundary. The 
defect can most likely be attributed to a lack of fusion created by insufficient melting. The presence of such defects introduces stress concentration sites which can be detrimental in the case of dynamic loading. Nonetheless, the sample produced with an $80 \mu \mathrm{m}$ layer thickness reached a density of approximately $99.9 \%$ based on the image analysis. Hence, even if the higher layer thickness leads to some flat lack of fusion defects, they are not abundant enough to affect the density value.

\subsection{Microstructure}

Figure 5 reveals that the produced samples are characterized by parabolic shaped melt pools, columnar grains, and a fine cellular structure. The images are presented in two orientations - namely normal and parallel-with respect to the building direction. Determining the exact size of the melt pool requires a more comprehensive study. However, as observable in Fig. 5a and d, a substantial enlargement in melt pool size is observed in the sample produced with an $80 \mu \mathrm{m}$ layer thickness. Both the shape and size of the melt pools are determined by the process parameters, namely the laser power, scan speed, hatch distance, and layer thickness (Ref 23-29). The increased melt pool size is consequently formed by the differences in process parameters.

As presented in Fig. $5 \mathrm{c}$ and $\mathrm{f}$, both the samples produced with $20 \mu \mathrm{m}$ and $80 \mu \mathrm{m}$ layer thickness present a fine cellular structure, with average cell sizes of $0.48 \pm 0.10 \mu \mathrm{m}$ and $0.69 \pm 0.21 \mu \mathrm{m}$, respectively. The cell size is affected by the solidification conditions (thermal gradient, cooling rate, and solidification front velocity), which are determined by the process parameters and component geometry. Faster solidification indicates finer cellular/dendritic structure. The increase in the cell size of the sample produced with $80 \mu \mathrm{m}$ layer thickness is a consequence of the slower solidification within the larger melt pools.

Figure 6 displays EBSD orientation maps for the samples produced with different layer thicknesses; these maps were acquired parallel to the building direction. As seen in Fig. 6a, the microstructure of the sample produced with $20 \mu \mathrm{m}$ layer thickness is characterized by large elongated grains aligned with the building direction. Many of the grains are extended beyond the layer thickness and span over several melt pool boundaries; hence, epitaxial grain growth has occurred. Furthermore, a strong preference in the $<101>$ direction is observed. The samples with $80 \mu \mathrm{m}$ layer thickness exhibited more random crystallographic orientation with smaller and less elongated grains, as displayed in Fig. 6b. It appears that the increased layer thickness and lower energy density limit the growth and preferential orientation. When using the lower energy density, fewer layers are re-melted, which reduces the epitaxial growth. In Fig. 6b, the grains appear as half-circular, with an appearance similar to that of the melt pools, indicating that the grains nucleate from the melt pool boundaries instead of grow in an epitaxial manner. Furthermore, the reduced energy density indicates that the time the materials remain at an elevated temperature is decreased, which appears to result in a smaller grain size.

As explained by Sun et al. (Ref 28), the melt pool shape and size represent an essential aspect of texture development in LPBF. At the bottom of the melt pools, the cells grow parallel to the build direction, and as the melt pool boundary becomes steeper, the texture begins to deviate from $<001>$ (i.e., becomes more random). At a certain point, the angle between the normal and building direction is approximately $45^{\circ}$, indicating that a predominant $<101>$ texture is formed. The differences in the preferential crystallographic orientation observed in this study can thus be related to the changes in melt pool size together with reduced epitaxial growth, since few layers have been re-melted.

It has previously been demonstrated that dislocation density is important for the properties of $316 \mathrm{~L}$ produced by L-PBF (Ref 2 ), and hence, Kernel average misorientation (KAM) maps were developed from the EBSD measurements (see Fig. 7).
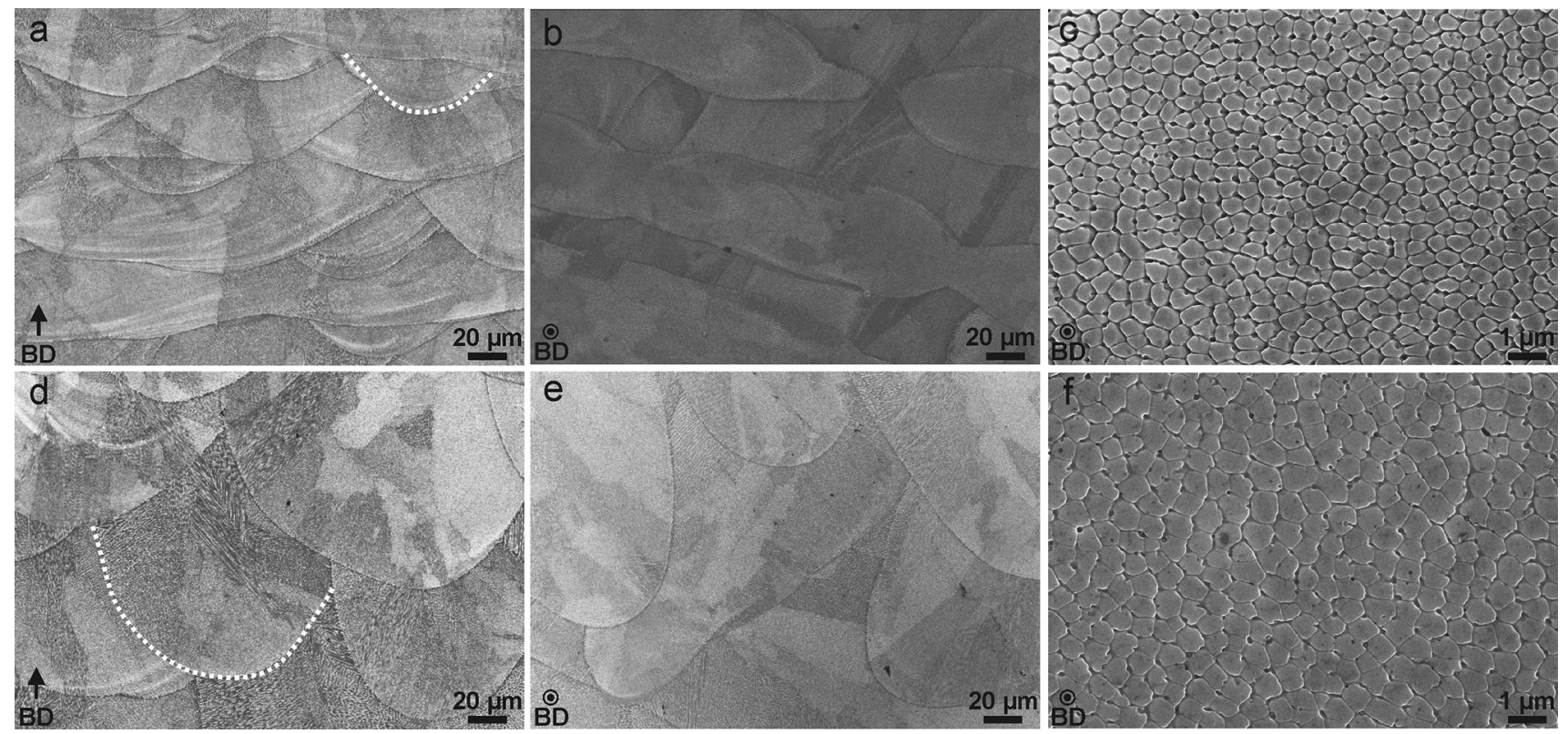

Fig. 5 SEM micrographs of the microstructure along and normal to the building direction of the samples produced with a layer thickness of $20 \mu \mathrm{m}(\mathrm{a}-\mathrm{c})$ and $80 \mu \mathrm{m}(\mathrm{b}-\mathrm{f})$. Two melt pools are marked in (a) and (c) to emphasize the enlarged size for the sample produced with $80 \mu \mathrm{m}$ layer thickness 

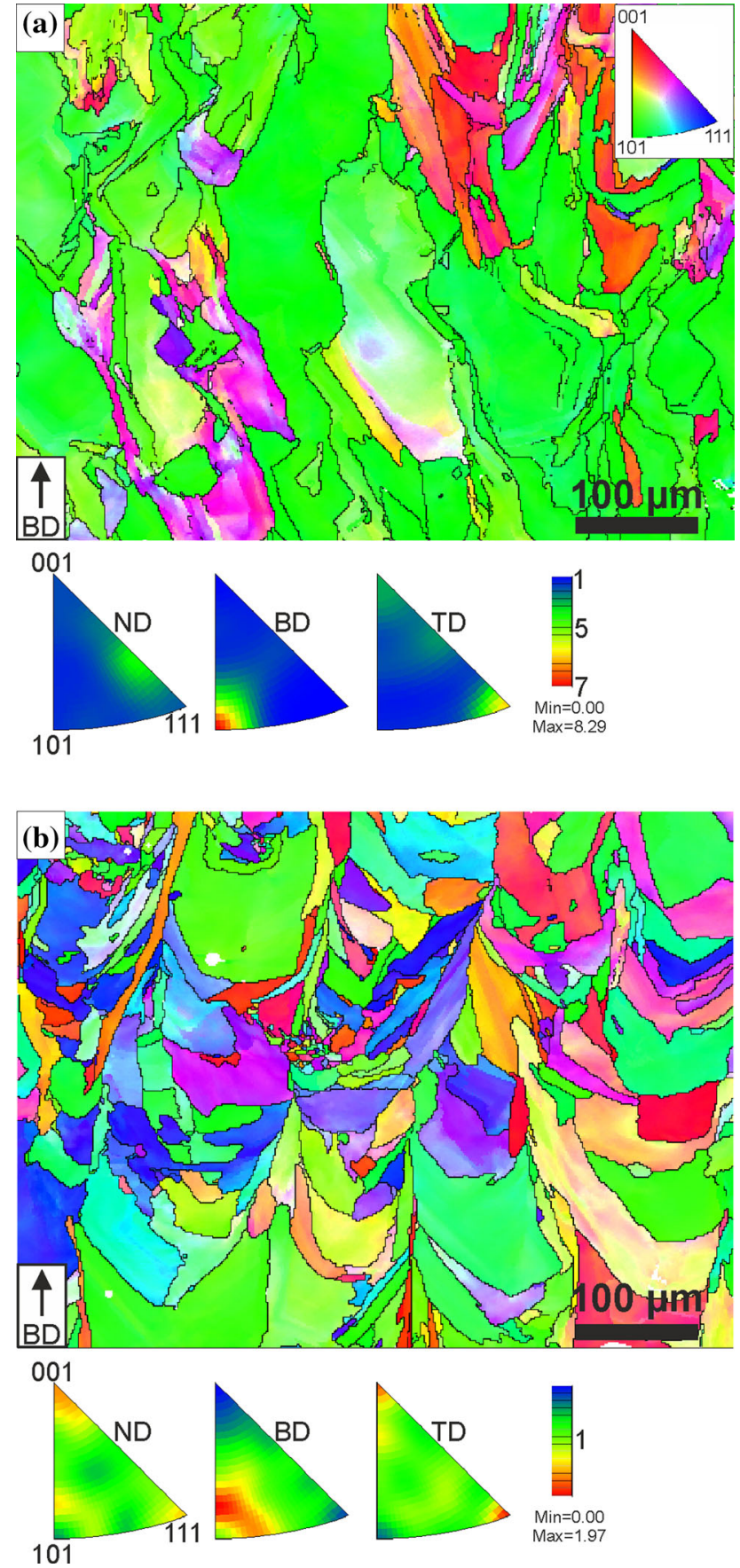

Fig. 6 EBSD orientation maps in IPF coloring and parallel to the building direction of samples produced with (a) $20 \mu \mathrm{m}$ layer thickness and (b) $80 \mu \mathrm{m}$ layer thickness

The KAM maps express the local misorientation in the sample, which can be seen in the color coding of the figure; this misorientation can then be used as an indication of a higher strain. The local misorientation range is set to be between 0 and $2^{\circ}$. Likewise, higher strains can be used as a qualitative measure for a high dislocation density (Ref 30$)$. Molybdenum is known to segregate to the cell boundary. As the molybdenum atom is larger than the iron atom, a local stress/strain field is generated at the cell boundary, which might affect the strain measurement but also nominally increase the number of dislocations (Ref 2, 31). As seen in Fig. 7a, the samples
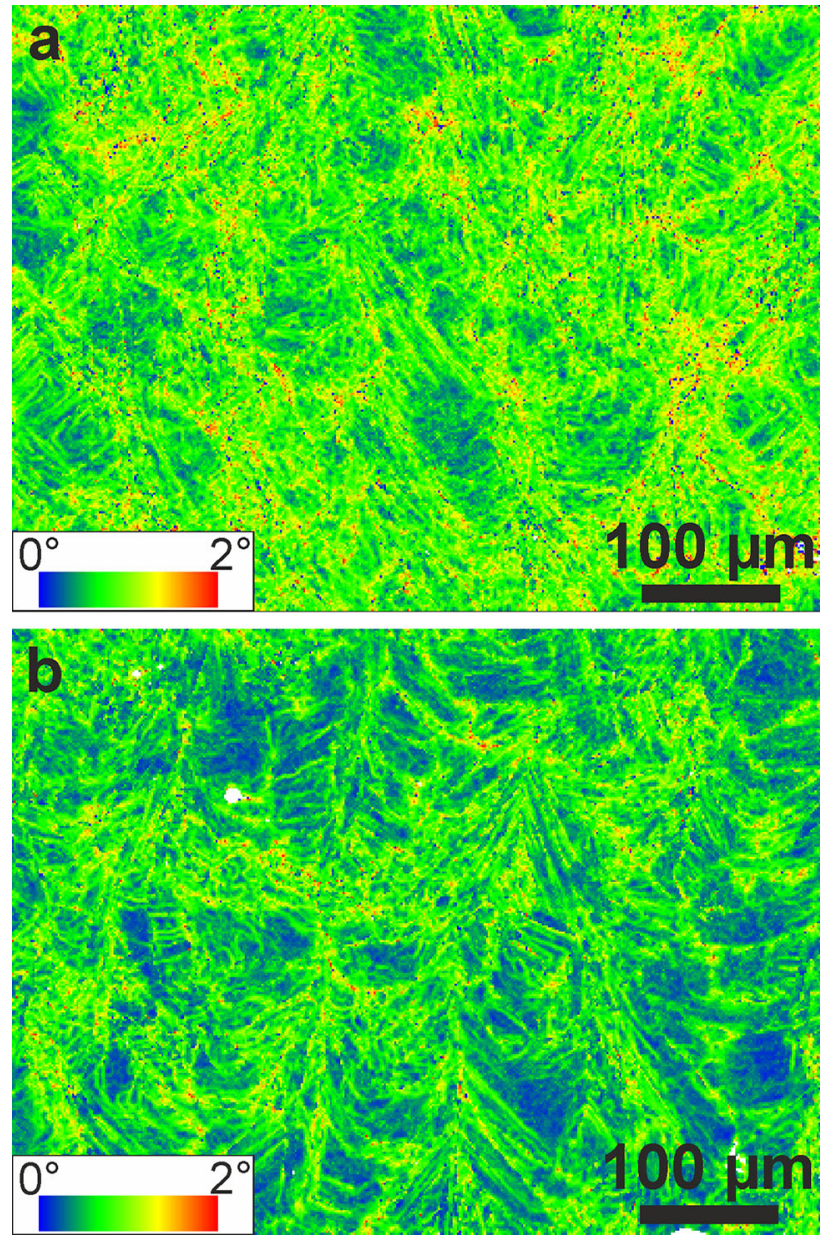

Fig. 7 Kernel average misorientation maps of samples produced with (a) $20 \mu \mathrm{m}$ layer thickness and (b) $80 \mu \mathrm{m}$ layer thickness

produced with $20 \mu \mathrm{m}$ layer thickness reveal more local misorientation compared with the samples produced with $80 \mu \mathrm{m}$ layer thickness (Fig. 7b). The results obtained from the KAM maps were affected by the step size, beam size, and the location where the map was obtained; therefore, XRD studies were conducted as a complement. Figure 8 presents the samples with three detectable diffraction peaks, namely $\{111\}$, $\{200\}$, and $\{220\}$, which is characteristic for the austenite phase (no other phases were observed). To evaluate the dislocation density, new scans were performed with a smaller step size $\left(0.001^{\circ}\right)$ and conducted over each specific peak. The dislocation density was then derived by following the procedure demonstrated by Yin et al. (Ref 32): using $\rho=k \frac{\varepsilon^{2}}{b^{2}}$, where $\varepsilon$ is the full width at half maximum broadening (obtained by linear fit), $\mathrm{b}$ is the Burgers vector and $\mathrm{k}=16.1$. The dislocation densities for the samples produced with $20 \mu \mathrm{m}$ and $80 \mu \mathrm{m}$ layer thickness were thereby estimated to be $1.9^{*} 10^{14} \mathrm{~m}^{-2}$ and $7.2 * 10^{14} \mathrm{~m}^{-2}$, respectively. This confirms the results obtained from the KAM maps (i.e., that samples produced with $20 \mu \mathrm{m}$ layer thickness have a higher density of dislocations than samples produced with $80 \mu \mathrm{m}$ layer thickness).

\subsection{Mechanical properties}

The tensile properties of the produced samples are presented in Fig. 9 and Table 5. Both samples exhibit approximately the 
same ultimate tensile strength (UTS), but the yield strength (YS) and elongation to fracture (ductility) are about 15\% and $30 \%$, respectively, and lower for the sample produced with $80 \mu \mathrm{m}$ layer thickness. Still, the sample produced with $80 \mu \mathrm{m}$ layer thickness exceeds the requirements for $316 \mathrm{~L}$, according to ASTM A240M-18 (see Table 5).

The high yield strength of $316 \mathrm{~L}$ samples produced with L$\mathrm{PBF}$ is explained by several microstructure features. For example, the dislocation movement can be hindered by grain

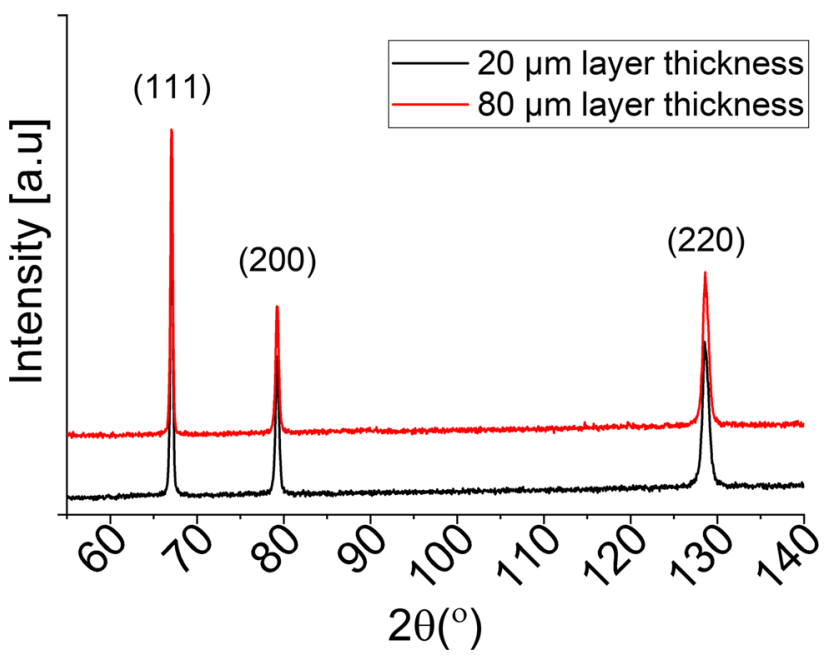

Fig. 8 The XRD patterns obtained from the as-built surface of the produced samples, indicating a fully austenitic sample in both cases

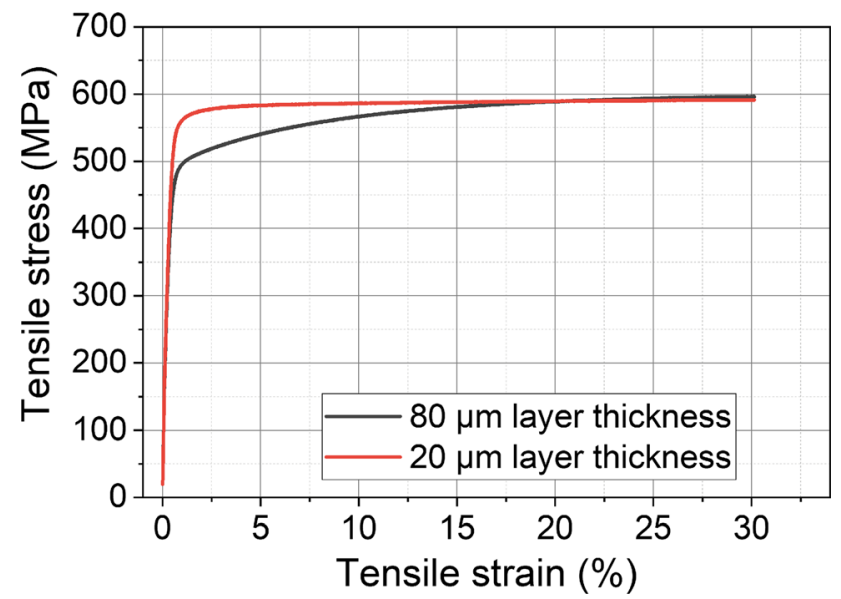

Fig. 9 Tensile properties of the samples produced with $20 \mu \mathrm{m}$ and $80 \mu \mathrm{m}$ layer thickness boundaries (Ref 33), other dislocations (Ref 33, 34), cells (Ref $35,36)$, and element segregation (Ref 36). It appears that the cells are considered to be the most significant feature for the tensile properties, as they contain both dislocations and segregated elements, effectively hindering the dislocation movement (Ref 2, 33, 36). The smaller cell size and higher dislocation density in the samples built with $20 \mu \mathrm{m}$ layer thickness are expected to provide a yield strength increase relative to that for the sample with $80 \mu \mathrm{m}$ layer thickness due to the increased interaction of dislocation pile-up in the cell boundaries. This was also reported by Wang et al. (Ref 37) and Wang et al. (Ref 2), who presented a linear dependency between decreasing cell size and increased tensile properties, consistent with the results presented in this study.

Apart from differences in yield strength, a slight difference in the strain-hardening rate between the samples was noted (see the black curve in Fig. 9). This could also be understood by the decreased cell size and increased dislocation density. Initially having a higher dislocation density in the unloaded stage means that the samples will be saturated with new dislocations more quickly, which prevents new dislocations from nucleating. The resistance to forming new dislocations reduces the strain hardening rate; however, as shown in both samples, strain hardening continues even at higher deformation but at a supposedly very low rate. This behavior was described by Wang et al. (Ref 2) and is associated with deformation by twinning and a cell-cell interaction. Wang et al. demonstrated that dislocations pile-up in the cell boundaries promoted deformation by twinning, which helped to sustain a steady strain hardening. This steady strain hardening then improves the ductility by allowing dislocations to move in the twin boundaries, which retards necking. In addition, Sun et al. (Ref 8 ) and Sinha et al. (Ref 38) demonstrated that $<101>$ oriented grains are more favorable for twinning. It is assumed that the sample built with $20 \mu \mathrm{m}$ layer thickness will deform by twinning to the greatest extent, as the sample exhibits a smaller cell size, higher dislocation density, and stronger $<101>$ texture. The observed higher yield strength and ductility is thereby supposed to be explained by increased twinning and decreased cell size.

However, the reduction in ductility is also associated with the previously observed lack of fusion defects (Fig. 4b). Figure 10 presents the fracture surface of the samples produced with both layer thicknesses. In both cases, a transgranular ductile fracture is the characteristic failure mechanism, with the presence of fine and deep dimples, representative of highductility samples. Occasionally, larger dimples with the presence of secondary phases were observed in both samples. Camille et al. (Ref 39) demonstrated via energy-dispersive xray spectroscopy, that these secondary phases were oxides rich in $\mathrm{Cr}, \mathrm{Mn}$, and $\mathrm{Si}$. These samples were produced with the same powder feedstock and in the same machine used in this study.

Table 5 Average tensile properties for the produced samples and strength requirements from the ASTM A240M-18 standard

\begin{tabular}{lccc}
\hline Layer thickness $(\boldsymbol{\mu m})$ & Yield strength & Ultimate tensile strength & Elongation at fracture \\
\hline 20 & $539 \pm 3.6$ & $606 \pm 3.5$ & $61 \pm 3.2$ \\
80 & $464 \pm 7.2$ & $605 \pm 3.4$ & $44 \pm 0.6$ \\
ASTM A240M-18 & 170 & 485 & 40 \\
\hline
\end{tabular}



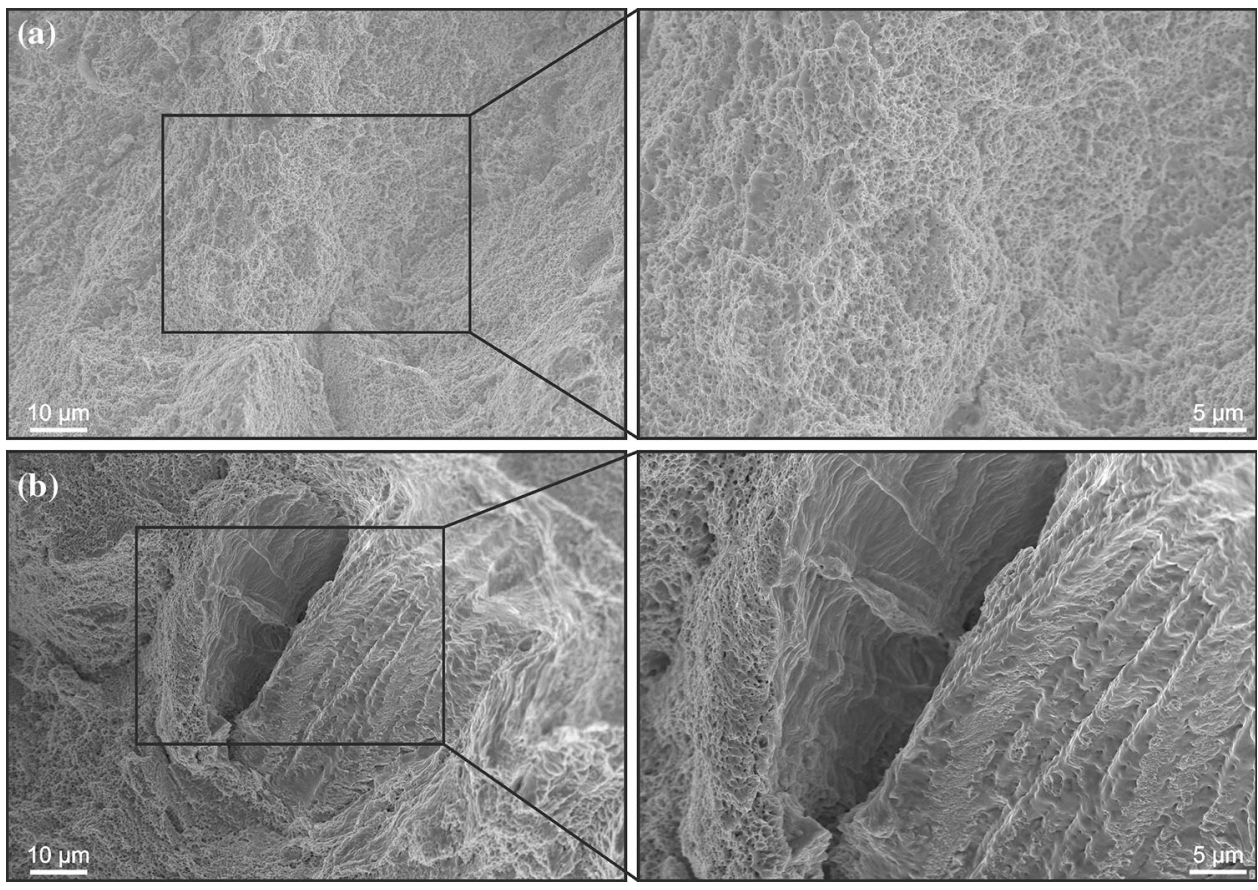

Fig. 10 SEM micrographs of the fracture surface of the sample produced with $20 \mu \mathrm{m}$ layer thickness (a) and $80 \mu \mathrm{m}$ layer thickness (b). (b) clearly indicates presence of the lack of fusion defects

Furthermore, the fracture surface analysis clearly demonstrates the reason for the observed difference in elongation between the samples. Figure $10 \mathrm{~b}$ presents a representative feature found on the fracture surface of the sample produced at $80 \mu \mathrm{m}$ layer thickness: the presence of large areas (up to $50 \mu \mathrm{m}$ in size), with clear decohesion between the adjacent layers.

The decohesion facets are orientated in the plane of the fracture surface and thus lack of fusion defects (since the samples was built vertically). The observed decohesion facets and the flat narrow cavities/porosity explain the absence of cohesion between the layers. These sites will act as internal crack initiation points and sites for preferable crack propagation, resulting in a reduced ductility for the sample built with the increased layer thickness.

\section{Conclusions}

This study demonstrated how to improve the productivity of laser powder bed fusion of stainless steel 316L austenitic stainless steel without significantly compromising the density, microstructure, or mechanical properties. Through a process window development involving the application of on-line process monitoring, a process window for increased productivity was found by increasing the layer thickness from $20 \mu \mathrm{m}$ to $80 \mu \mathrm{m}$. The obtained results clearly indicate that the build time can be shortened by a factor of four, resulting in a corresponding increase in productivity. Both layer thicknesses achieved a density greater than $99.9 \%$, but lack of fusion defects in samples produced with an $80 \mu \mathrm{m}$ layer thickness was noticed. The samples produced with $20 \mu \mathrm{m}$ layer thickness exhibited a predominant $<101>$ orientation of the large elongated grains, while the microstructure of the samples produced with $80 \mu \mathrm{m}$ layer thickness had a random texture with fewer elongated grains. The increased layer thickness decreased the YS from about $540 \mathrm{MPa}$ to about $460 \mathrm{MPa}$ and was associated with a decreased cell size and decreased dislocation density. The ultimate tensile strength was approximately $600 \mathrm{MPa}$ for both the samples. Thus, strain hardening appears to be slightly more prominent for the samples built with $80 \mu \mathrm{m}$ layer thickness. In addition, the elongation to fracture decreased from $61 \%$ to $44 \%$ for samples produced with an $80 \mu \mathrm{m}$ layer thickness. Still, for the larger layer thickness, the mechanical properties can well satisfy the standard specifications for coldrolled stainless steel 316L, according to ASTM A240M-18.

\section{Acknowledgments}

This work was conducted in the framework of the Centre for Additive Manufacturing - Metal $\left(\mathrm{CAM}^{2}\right)$ and AMLIGHT project within the Innovation program Metallic Materials, both supported by Swedish Governmental Agency of Innovation Systems (Vinnova). In addition, this project received funding from the European Union's Horizon 2020 research and innovation program under Grant Agreement n'820774. Dr Eric Tam is greatly acknowledged for the contribution to XRD measurements.

\section{Funding}

Open access funding provided by Chalmers University of Technology.

\section{Open Access}

This article is licensed under a Creative Commons Attribution 4.0 International License, which permits use, sharing, adaptation, distribution and reproduction in any medium or format, as long as 
you give appropriate credit to the original author(s) and the source, provide a link to the Creative Commons licence, and indicate if changes were made. The images or other third party material in this article are included in the article's Creative Commons licence, unless indicated otherwise in a credit line to the material. If material is not included in the article's Creative Commons licence and your intended use is not permitted by statutory regulation or exceeds the permitted use, you will need to obtain permission directly from the copyright holder. To view a copy of this licence, visit http://creativecommons.org/licenses/by/4.0/.

\section{References}

1. W.E. Frazier, Metal Additive Manufacturing: A Review, J. Mater. Eng. Perform., 2014, 23(6), p 1917-1928

2. Y.M. Wang, T. Voisin, J.T. McKeown, J. Ye, N.P. Calta, Z. Li, Z. Zeng, Y. Zhang, W. Chen, T.T. Roehling, R.T. Ott, M.K. Santala, P.J.J.J. Depond, M.J. Matthews, A.V. Hamza, and T. Zhu, Additively Manufactured Hierarchical Stainless Steels with High Strength and Ductility, Nat. Mater., 2018, 17(1), p 63-70. https://doi.org/10.1038/ NMAT5021

3. M. Attaran, The Rise of 3-D Printing: The Advantages of Additive Manufacturing over Traditional Manufacturing, Bus. Horiz., 2017, 60(5), p 677-688. https://doi.org/10.1016/j.bushor.2017.05.011

4. M. Baumers, P. Dickens, C. Tuck, and R. Hague, The Cost of Additive Manufacturing: Machine Productivity, Economies of Scale and Technology-Push, Technol. Forecast. Soc. Change, 2016, 102, p 193-201. h ttps://doi.org/10.1016/j.techfore.2015.02.015

5. C.R. Cunningham, S. Wikshåland, F. Xu, N. Kemakolam, A. Shokrani, V. Dhokia, and S.T. Newman, Cost Modelling and Sensitivity Analysis of Wire and Arc Additive Manufacturing, Procedia Manuf., 2017, 11(December), p 650-657

6. S. Greco, K. Gutzeit, H. Hotz, B. Kirsch, and J.C. Aurich, Selective Laser Melting (SLM) of AISI, 316L-Impact of Laser Power, Layer Thickness, and Hatch Spacing on Roughness, Density, and Microhardness at Constant Input Energy Density, Int. J. Adv. Manuf. Technol., 2020, 108(5-6), p 1551-1562

7. L. Liu, Q. Ding, Y. Zhong, J. Zou, J. Wu, Y.L. Chiu, J. Li, Z. Zhang, Q. $\mathrm{Yu}$, and Z. Shen, Dislocation Network in Additive Manufactured Steel Breaks Strength-Ductility Trade-Off, Mater. Today, 2018, 21(4), p 354 361. https://doi.org/10.1016/j.mattod.2017.11.004

8. Z. Sun, X. Tan, S.B. Tor, and C.K. Chua, Simultaneously Enhanced Strength and Ductility for 3D-Printed Stainless Steel 316L by Selective Laser Melting, NPG Asia Mater, 2018, 10(4), p 127-136. https://doi. org/10.1038/s41427-018-0018-5

9. A. Leicht, M. Rashidi, U. Klement, and E. Hryha, Effect of Process Parameters on the Microstructure, Tensile Strength and Productivity of 316L Parts Produced by Laser Powder Bed Fusion, Charact, Mater, 2020, https://doi.org/10.1016/j.matchar.2019.110016

10. E. Liverani, S. Toschi, L. Ceschini, and A. Fortunato, Effect of Selective Laser Melting (SLM) Process Parameters on Microstructure and Mechanical Properties of 316L Austenitic Stainless Steel, J. Mater Process. Technol., 2017, 249, p 255-263. https://doi.org/10.1016/j.jma tprotec.2017.05.042

11. S. Tsopanos, R.A.W. Mines, S. McKown, Y. Shen, W.J. Cantwell, W. Brooks, and C.J. Sutcliffe, The Influence of Processing Parameters on the Mechanical Properties of Selectively Laser Melted Stainless Steel Microlattice Structures, J. Manuf. Sci. Eng., 2010, 132(4), p 041011. h ttps://doi.org/10.1115/1.4001743

12. S.S. Babu, L. Love, R. Dehoff, W. Peter, T.R. Watkins, and S. Pannala, Additive Manufacturing of Materials: Opportunities and Challenges, MRS Bull., 2015, 40(12), p 1154-1161

13. Z. Sun, X. Tan, S.B. Tor, and W.Y. Yeong, Selective Laser Melting of Stainless Steel 316L with Low Porosity and High Build Rates, Mater. Des., 2016, 104, p 197-204. https://doi.org/10.1016/j.matdes.2016.05.035

14. S. Wang, Y. Liu, W. Shi, B. Qi, J. Yang, F. Zhang, D. Han, and Y. Ma, Research on High Layer Thickness Fabricated of $316 \mathrm{~L}$ by Selective Laser Melting, Materials., 2017, 10(9), p 1055

15. X. Shi, S. Ma, C. Liu, C. Chen, Q. Wu, X. Chen, and J. Lu, Performance of High Layer Thickness in Selective Laser Melting of Ti6A14V, Materials, 2016, 9(12), p 1-15
16. M. Ma, Z. Wang, M. Gao, and X. Zeng, Layer Thickness Dependence of Performance in High-Power Selective Laser Melting of 1Cr18Ni9Ti Stainless Steel, J. Mater. Process. Technol., 2015, 215(1), p 142-150. h ttps://doi.org/10.1016/j.jmatprotec.2014.07.034

17. L. Jinhui, L. Ruidi, Z. Wenxian, F. Liding, and Y. Huashan, Study on Formation of Surface and Microstructure of Stainless Steel Part Produced by Selective Laser Melting, Mater. Sci. Technol., 2010, 26(10), p 1259-1264. https://doi.org/10.1179/174328409X441300

18. Y. Tian, D. Tomus, A. Huang, X. Wu, Experimental and Statistical Analysis on Process Parameters and Surface Roughness Relationship for Selective Laser Melting of Hastelloy X. Rapid Prototyp. J., 2019, 25(7), p 1309-1318

19. C. Qiu, C. Panwisawas, M. Ward, H.C. Basoalto, J.W. Brooks, and M.M. Attallah, On the Role of Melt Flow into the Surface Structure and Porosity Development during Selective Laser Melting, Acta Mater, 2015, 96, p 72-79

20. Q.B. Nguyen, D.N. Luu, S.M.L. Nai, Z. Zhu, Z. Chen, and J. Wei, The Role of Powder Layer Thickness on the Quality of SLM Printed Parts, Arch. Civ. Mech. Eng., 2018, 18(3), p 948-955

21. German R.M.: Powder Metallurgy Science. 2. ed., Metal Powder Industries Federation (1994), https://search.ebscohost.com/login.aspx? direct $=$ true $\&$ AuthType $=\mathrm{sso} \& \mathrm{db}=\mathrm{cat} 07470 \mathrm{a} \& \mathrm{AN}=\mathrm{clc} .3 \mathrm{~b} 0 \mathrm{a} 3 \mathrm{a} 34.1055$. 428f.b36c.01e 768155b07\&site=eds-live\&scope $=$ site \&custid $=$ s391197 $9 \&$ authtype $=$ sso\&group $=$ main \&profile $=$ eds

22. W.E. King, H.D. Barth, V.M. Castillo, G.F. Gallegos, J.W. Gibbs, D.E. Hahn, C. Kamath, and A.M. Rubenchik, Observation of KeyholeMode Laser Melting in Laser Powder-Bed Fusion Additive Manufacturing, J. Mater. Process. Technol., 2014, 214(12), p 2915-2925. h ttps://doi.org/10.1016/j.jmatprotec.2014.06.005

23. R. Acharya, J.A. Sharon, and A. Staroselsky, Prediction of Microstructure in Laser Powder Bed Fusion Process, Acta Mater., 2017, 124, p 360-371. https://doi.org/10.1016/j.actamat.2016.11.018

24. M.L. Montero-Sistiaga, S. Pourbabak, J. Van Humbeeck, D. Schryvers, and K. Vanmeensel, Microstructure and Mechanical Properties of Hastelloy X Produced by HP-SLM (High Power Selective Laser Melting), Mater. Des., 2019, 165(2019), p 107598. https://doi.org/10. 1016/j.matdes.2019.107598

25. J. Metelkova, Y. Kinds, K. Kempen, C. de Formanoir, A. Witvrouw, and B. Van Hooreweder, On the Influence of Laser Defocusing in Selective Laser Melting of 316L, Addit. Manuf., 2018, 23, p 161-169. https://doi.org/10.1016/j.addma.2018.08.006

26. L.E. Criales, Y.M. Arısoy, B. Lane, S. Moylan, A. Donmez, and T. Özel, Laser Powder Bed Fusion of Nickel Alloy 625: Experimental Investigations of Effects of Process Parameters on Melt Pool Size and Shape with Spatter Analysis, Int. J. Mach. Tools Manuf, 2016, 2017(121), p 22-36

27. W. Shifeng, L. Shuai, W. Qingsong, C. Yan, Z. Sheng, and S. Yusheng, Effect of Molten Pool Boundaries on the Mechanical Properties of Selective Laser Melting Parts, J. Mater. Process. Technol., 2014, 214(11), p 2660-2667. https://doi.org/10.1016/j.jmatprotec.2014.06.0 02

28. S.-H. Sun, T. Ishimoto, K. Hagihara, Y. Tsutsumi, T. Hanawa, and T. Nakano, Excellent Mechanical and Corrosion Properties of Austenitic Stainless Steel with a Unique Crystallographic Lamellar Microstructure via Selective Laser Melting, Scr. Mater., 2019, 159, p 89-93. https://d oi.org/10.1016/j.scriptamat.2018.09.017

29. O. Andreau, I. Koutiri, P. Peyre, J.D. Penot, N. Saintier, E. Pessard, T. De Terris, C. Dupuy, and T. Baudin, Texture Control of 316L Parts by Modulation of the Melt Pool Morphology in Selective Laser Melting, $J$. Mater. Process. Technol., 2019, 264, p 21-31. https://doi.org/10.1016/j. jmatprotec.2018.08.049

30. D. Jorge-Badiola, A. Iza-Mendia, and I. Gutiérrez, Evaluation of Intragranular Misorientation Parameters Measured by EBSD in a Hot Worked Austenitic Stainless Steel, J. Microsc., 2007, 228(3), p 373383

31. K. Saeidi, X. Gao, F. Lofaj, L. Kvetková, and Z.J.J. Shen, Transformation of Austenite to Duplex Austenite-Ferrite Assembly in Annealed Stainless Steel 316L Consolidated by Laser Melting, J. Alloys Compd., 2015, 633, p 463-469

32. Y.J. Yin, J.Q. Sun, J. Guo, X.F. Kan, and D.C. Yang, Mechanism of High Yield Strength and Yield Ratio of 316 L Stainless Steel by Additive Manufacturing, Mater. Sci. Eng., A, 2019, 744, p 773-777

33. M.S. Pham, B. Dovgyy, and P.A. Hooper, Twinning Induced Plasticity in Austenitic Stainless Steel 316L Made by Additive Manufacturing, 
Mater. Sci. Eng., A, 2017, 704, p 102-111. https://doi.org/10.1016/j. msea.2017.07.082

34. K. Saeidi, X. Gao, Y. Zhong, and Z.J.J. Shen, Hardened Austenite Steel with Columnar Sub-Grain Structure Formed by Laser Melting, Mater. Sci. Eng., A, 2015, 625, p 221-229. https://doi.org/10.1016/j.msea. 2014.12.018

35. D. Wang, C. Song, Y. Yang, and Y. Bai, Investigation of Crystal Growth Mechanism during Selective Laser Melting and Mechanical Property Characterization of 316L Stainless Steel Parts, Mater. Des., 2016, 100, p 291-299. https://doi.org/10.1016/j.matdes.201 6.03.111

36. Y. Zhong, L. Liu, S. Wikman, D. Cui, and Z. Shen, Intragranular Cellular Segregation Network Structure Strengthening 316L Stainless Steel Prepared by Selective Laser Melting, J. Nucl. Mater, 2016, 470, p $170-178$

37. X. Wang, J.A. Muñiz-Lerma, O. Sánchez-Mata, M. Attarian Shandiz, and M. Brochu, Microstructure and Mechanical Properties of Stainless
Steel 316L Vertical Struts Manufactured by Laser Powder Bed Fusion Process, Mater. Sci. Eng., A, 2018, 736, p 27-40. https://doi.org/10. 1016/j.msea.2018.08.069

38. S. Sinha, J.A. Szpunar, N.A.P. Kiran Kumar, and N.P. Gurao, Tensile Deformation of 316L Austenitic Stainless Steel Using In-Situ Electron Backscatter Diffraction and Crystal Plasticity Simulations, Mater. Sci. Eng., A, 2015, 637, p 48-55. https://doi.org/10.1016/j.msea.2015.04. 005

39. C. Pauzon, E. Hryha, P. Forêt, and L. Nyborg, Effect of Argon and Nitrogen Atmospheres on the Properties of Stainless Steel 316 L Parts Produced by Laser-Powder Bed Fusion, Mater. Des., 2019, 179, p 107873

Publisher's Note Springer Nature remains neutral with regard to jurisdictional claims in published maps and institutional affiliations. 